\title{
MEMBANGUN SINERGITAS ANTAR PELAKU DALAM PEMBERDAYAAN MASYARAKAT PERIKANAN MELALUI KLINIK IPTEK MINA BISNIS (Studi Kasus pada Pelaksanaan Klinik Iptek Mina Bisnis di Kabupaten Subang)
}

\author{
*Nendah Kurniasari \\ Balai Besar Penelitian Sosial Ekonomi Kelautan dan Perikanan \\ Gedung Balitbang KP I Lt. 4 \\ Jalan Pasir Putih Nomor 1 Ancol Timur, Jakarta Utara \\ Telp: (021) 64711583 Fax: 64700924 \\ *e-mail: nendahkurniasari@gmail.com \\ Diterima 8 Juli 2014- Disetujui 2 Nopember 2014
}

\begin{abstract}
ABSTRAK
Sinergitas antara pelaku pemberdayaan merupakan hal mendasar dalam pelaksanaan sebuah program pemberdayaan agar dapat berjalan efektif dan berkesinambungan. Makalah ini bertujuan untuk menggambarkan prinsip-prinsip dan langkah strategis membangun sinergitas yang harus ditempuh oleh KIMBis dalam menjalankan fungsinya sebagai wadah pemberdayaan masyarakat perikanan. Penelitian dilaksanakan di Subang pada Tahun 2013. Penelitian merupakan action research dimana kegiatan yang dilakukan adalah pemberdayaan masyarakat pesisir subang melalui kelembagaan KIMBis (Klinik Iptek Mina Bisnis). Data diambil melalui wawancara, dan observasi berkelanjutan terhadap jalannya KIMBis Subang. Data kemudian dianalisis menggunakan analisis deskriptif. Terdapat tiga prinsip dalam membangun sinergitas antar pelaku pelaksanaan KIMbis yaitu partisipatif yang mengarah pada emansipatif dan problem-posing education. Terkait dengan pelaksanaan prinsip tersebut, maka langkah strategis yang harus dilaksanakan adalah proses pembentukan harus melibatkan pemangku kepentingan lokal yang terkait dengan pemberdayaan masyarakat, membuat program kerja yang mengarah pada kemandirian KIMBis yang dilakukan secara partisipatif, melakukan sinkronisasi program dengan instasi/lembaga terkait, membangun percaya diri para pengurus KIMBis dalam membangun jaringan kerja secara mandiri,membuat pelaporan terhadap instasi/lembaga mitra, dan menjaga hubungan non formaluntuk menumbuhkan ikatan emosional.
\end{abstract}

Kata kunci: sinergitas, Klinik Iptek Mina Bisnis, pemberdayaan

Abstract : Building Synergity Among Actors of Fisheries Community Empowerment Through Klinik Iptek Mina Bisnis (Case Study on Klinik Iptek Mina Bisnis Program in Subang District) by: Nendah Kurniasari

Synergy among the empowerment actors are central to the implementation of an empowerment program to be effective and sustainable. This paper aims to describe the principles and strategic steps to build synergy that must be taken by KIMBis in its function as a forum for community empowerment fisheries. Research carried out in Subang in 2013. Research is an action research where activities carried out are the coastal community empowerment through KIMBis institutional. Data captured through interviews, and continuous observation of the course of KIMBis Subang. Data were analyzed using descriptive analysis, combined with the theories of empowerment. There are three principles in building synergy between actors in KIMbis implementation namely partnership, participatory which leads to emancipatory and problem-posing education. The implementation of these principles, the strategic steps that should be implemented is the formation process should involve local stakeholders related to community development, create a work program leading to the independence of KIMBis that is participatory, synchronize programs with institutions, building trust KIMBis administrators themselves in building a network of independent, making reporting partner institutions, non-formal and maintain relationships to foster emotional bonding.

Keywords : synergity, Klinik Iptek Mina Bisnis, empowerment

\section{PENDAHULUAN}

Sampai saat ini, Indonesia sebagai negara maritim belum bisa dikatakan telah berhasil mensejahterakan masyarakat nelayan. Masyarakat nelayan Indonesia masih dinilai sebagai kelompok masyarakat yang termarginalkan dari kelompok masyarakat lain. Secara ekonomi, nelayan Indonesia lekat dengan label The poorest of the poor. Secara sosial nelayan Indonesia menempati posisi marginal dan mempunyai status sosial yang lebih rendah dibandingkan dengan kelompok masyarakat lainnya. Sedangkan secara budaya nelayan Indonesia menyandang stereotif negatif sebagai penyebab kekumuhan daerah pantai dengan berbagai perilakunya.

Kondisi tersebut bukan sepenuhnya disebabkan karena ketidakpedulian pemerintah terhadap pembangunan wilayah pesisir dan kehidupan nelayan. Undang-Undang No 31 Tahun 2004 tentang perikanan, merupakan amanah negara kepada pemerintah untuk meningkatkan taraf hidup masyarakat pesisir 
diantaranya adalah nelayan dan pembudidaya berskala kecil. Untuk melaksanakan amanat itu, maka pemerintah melalui berbagai kementeriannya telah menyelenggarakan program-program pemberdayaan. Beberapa program terkait dengan peningkatan kesejahteraan nelayan adalah Pemberdayaan Ekonomi Masyarakat Pesisir (PEMP), Pengembangan Usaha Budidaya Ikan Skala Kecil melalui Dana Penguatan Modal, Pengembangan Usaha Perikanan Tangkap melalui Program Optimalisasi Usaha, Pengembangan Usaha Pengolahan dan Pemasaran Hasil Perikanan melalui Program Klasterisasi Pengolahan dan Pemasaran Hasil Perikanan dan Program Nasional Pemberdayaan Masyarakat Mandiri Kelautan dan Perikanan (PNPM-KP).

Selain pemerintah, beberapa lembaga nonpemerintah (LSM) pun turut melakukan berbagai usaha pemberdayaan nelayan diantaranya adalah KIARA, LSM Dian, dll. Namun demikian Kurniasari dan Reswaty (2011) mengungkapkan bahwa banyaknya program-program pemberdayaan untuk masyarakat pesisir ternyata tidak serta merta diikuti oleh perkembangan kesejahteraan nelayan.Meskipun ada, laju perkembangan tersebut tidak sebanding dengan jumlah korbanan yang telah dikeluarkan.

Pertanyaan yang muncul dari fakta tersebut adalah mengapa hasil pemberdayaan yang telah dilakukan tidak sebanding dengan korbanan yang dikeluarkan? Salah satu penyebabnya adalah tidak adanya sinkronisasi antara program-program pemberdayaan, sehingga banyak kegiatan yang overlap. Selain itu minimnya data dan informasi kebutuhan nelayan yang sangat terbatas tidak jarang mengakibatkan program bantuan tidak sesuai dengan kebutuhan nelayan sehingga bantuan menjadi tidak bermanfaat.

Untuk mewujudkan hal tersebut maka diperlukan sebuah lembaga yang mampu menjembatani sinkronisasi program-program tersebut sehingga program pemberdayaan dapat berjalan efektif, efisien dan berkelanjutan. Klinik Iptek Mina Bisnis (KIMBis) merupakan sebuah lembaga yang diinisiasi oleh Balitbang KP dimana salah satu programnya adalah membangun sinergitas antar lembaga yang sudah ada baik itu SKPP, SKPD dan swasta untuk meningkatkan kesejahteraan masyarakat dengan mengoptimalkan pemanfaatan program perbantuan.Permasalahan perikanan yang sangat kompleks dan bersifat lokal, menjadi alasan kenapa KIMBis dibentuk dengan cakupan wilayah kabupaten.

Makalah ini bertujuan untuk memberikan gambaran, bagaimana KIMBis melakukan upaya membangun sinergitas antar stakeholder dalam melaksanakan program pemberdayaan masyarakat nelayan dan pembudidaya. Gambaran ini diharapkan dapat bermanfaat sebagai bahan masukan atau bahan pertimbangan berbagai pihak baik untuk perbaikan pelaksanaan KIMBis maupun untuk kegiatan pemberdayaan yang lain agar program pemberdayaan yang dilakukan dapat berjalan efektif, efisien, berkeadilan dan berkelanjutan.

\section{METODOLOGI}

Penelitian didasarkan pada data hasil wawancara dan observasi peneliti terhadap pelaksanaan Klinik Iptek Mina Bisnis di Kabupaten Subang pada kurun waktu Februari sampai dengan Juli 2013. Data kemudian dianalisis secara deskriptif kualitatif berdasarkan teoriteori pemberdayaan. Display data dikelompokkan menjadi dua bagian yaitu prinsip-prinsip membangun sinergitas dan langkah-langkah strategis yang dilakukan oleh KIMBis Subang dalam membangun sinergitas tersebut.

\section{PRINSIP KIMBIS DALAM MEMBANGUN SINERGITAS}

Upaya KIMBis Subang membangun sinergitas program antar pelaku pemberdayaan didasarkan pada prinsip partership, partisipatif yang mengarah pada emansipatif dan problem-posing education.

\section{a. Partnership}

Pemberdayaan masyarakat sangat terkait erat dengan kondisi sebuah masyarakat dimana kondisi sekarang tidak sesuai dengan kondisi yang diharapkan. Dengan kata lain upaya pemberdayaan dilakukan karena adanya ketidak berdayaan sasaran untuk meraih harapan. Hal tersebut membawa konsekuensi bahwa dalam pemberdayaan memerlukan campur tangan pihak di luar sasaran untuk membantu sasaran agar berdaya sehingga harapan dapat terwujud. Oleh karenanya, pemberdayaan merupakan sebuah upaya yang harus dilakukan secara bersama-sama. Ife (2002) mengatakan bahwa empowerment is a collaborative process, with the people and the practitioner working together as a partner. Jadi dalam proses pemberdayaan ada dua pihak yang terlibat yaitu masyarakat yang mempunyai keinginan mewujudkan harapan dan pihak yang akan menjadi pengungkit atau praktisi usaha pemberdayaan tersebut. Seringkali pihak praktisi ini bukanlah pelaku tunggal tetapi banyak lembaga yang terlibat. Sehingga sinkronisasi antar pelaku sebagai pihak yang memberdayakan atau practitioner dalam membuat program pemberdayaan yang ditujukan untuk satu kelompok masyarakat yang sama menjadi sangat penting untuk dilakukan.

Pernyataan Ife (2002) di atas menunjukkan bahwa sinergitas akan tercapai bila hubungan yang dijalin bersifat partnership atau kemitraan. Artinya, antara masyarakat dan praktisi diposisikan sebagai rekan kerja, bukan sebagai atasan dan bawahan. Dengan demikian, tidak ada gap yang dapat menjadi penghalang keduanya untuk berkolaborasi mewujudkan upaya pemberdayaan sehingga diharapkan proses pemberdayaan dapat lebih efektif dan efisien. 


\section{b. Partisipatif yang mengarah pada emansipatif}

Selain prinsip partnership, dalam sinkronisasi program harus menjunjung tinggi prinsip partisipasi masyarakat. Masyarakat sudah seharusnya diberi kebebasan untuk menentukan harapan-harapan yang ingin ia wujudkan dan pilihan terhadap cara-cara yang akan dilakukan sesuai dengan norma dan nilai-nilai yang dianut oleh masyarakat tersebut. Hal ini dungkapkan oleh ife (2002) bahwa people must participate in their own empowerment; goals, means, and outcomes must be self defined.Dalam perkembagannya prinsip partisipatif ini harus berkembang ke arah emansipatif. Karena masyarakat harus diarahkan untuk mencapai kemandirian. Dengan kata lain, dalam upaya pemberdayaan, peran pemerintah harus berangsur berkurang sehingga masyarakat mempunyai kemampuan dan kepercayaan diri untuk memberdayakan dirinya.

Prijono dan Pranaka (1996) memberikan tahapantahapan yang harus dilakukan dalam pemberdayaan masyarakat, yaitu pertama tahap inisial yaitu dari pemerintah, oleh pemerintah dan untuk rakyat. Kedua adalah tahap partisipatoris yaitu dari pemerintah bersama rakyat, oleh pemerintah bersama rakyat, dan untuk rakyat. Sedangkan ketiga adalah tahap emansipatori yaitu dari rakyat, oleh rakyat, untuk rakyat dan didukung oleh pemerintah bersama rakyat.

Aplikasinya dalam pelaksanaan KIMBis, proses inisiasi dilakukan oleh Badan Penelitian dan Pengembangan Kelautan dan Perikanan Kementerian Kelautan dan Perikanan dimana Balai Besar Penelitian Sosial Ekonomi Kelautan dan Perikanan sebagai koordinator pelaksanaan KIMBis. Tahap partisipatoris dimulai sejak pembentukan KIMBis, penentuan kepengurusan, analisis kebutuhan, pembuatan program kerja, pelaksaan program kerja, menjalin kemitraan dengan para stakeholder, serta kegiatan-kegiatan lain sampai Tahun ke tiga.

Sebagai sebuah lembaga, KIMBis merupakan sebuah lembaga yang dibentuk secara partisipatif oleh para pemangku kepentingan dengan cara mengundang perwakilan masyarakat dari setiap RW, aparat desa, dan lembaga kemasyarakatan yang ada di wilayah sasaran. Sedangkan lokasi KIMBis merupakan hasil diskusi dengan SKPD setempat.

Sebagai pusat kegiatan, KIMBis pun melakukan sinergitas dengan melakukan kerjasama dengan SKPD, Satker lingkup KKP dan dunia usaha. Sebagai langkah awal, KIMBis melakukan FGD dengan para SKPD terkait untuk mensinergikan kegiatan KIMBis dengan program kerja SKPD dan Satker KKP. Hasil dari kegiatan tersebut adalah terdapat beberapa kegiatan KIMBis yang dapat disinergikan dengan kegiatan Dinas KP Subang sehingga kegiatan dapat berjalan lebih efektif, diantaranya adalah dari 7 rencana kegiatan pelatihan yang menjadi program kerja KIMBis, tiga diantaranya dapat memanfaatkan program perbantuan dari Dinas Kelautan dan Perikanan Kabupaten Subang. Kegiatan pemanfaatan program perbantuan dari Dinas Kelautan dan Perikanan adalah pelatihan perbengkelan kapal dan pelatihan keterampilan pemanfaatan kulit kerang untuk kerajinan tangan.

Menjelang tahun ke empat, merupakan masa exit strategy untuk mempersiapkan KIMBis pada tahap emansipatori, yaitu tahap tinggal landas dimana pada tahap ini KIMBis diharapkan mampu mandiri. Peran lembaga pemerintah adalah sebagai pendukung kegiatan-kegiatan KIMBis.Jadi, kolaborasi yang kemudian dibangun harus mampu menciptakan sebuah lembaga mandiri yang merupakan representasi dari masyarakat aktif. Masyarakat aktif menurut Etzioni dalam Poloma (1979) adalah masyarakat yang menguasai dunia sosial mereka. Lebih lanjut Etzioni mengatakan bahwa dalam dunia yang demikian manusia adalah pencipta, dapat membentuk masyarakat menanggulangi kebutuhannya. Berdasarkan hal tersebut, maka pada KIMBis yang telah mandiri, peran pengurus KIMBis pusat tidak lagi dominan hanya sebagai pendukung kegiatan KIMBis. KIMBis harus bisa menjalin jejaring kerja baik dengan lembaga keuangan, pemasaran, penelitian, dll secara mandiri. Oleh karenanya, sebelum lepas landas, pengurus KIMBis perlu dibekali bagaimana membangun jaringan dan bersinergi dengan para pelaku pemberdayaan.

\section{c. KIMBis Sebagai sarana Problem-Posing Education}

Pelaksanaan KIMBis pada dasarnya merupakan sebuah upaya pendidikan dimana bukan dalam pengertian transfer pengetahuan namun merupakan upaya bersama untuk menemukan pengetahuan. Sehingga hubungan yang terjadi bukan seperti guru dan murid, tetapi mempunyai kedudukan yang sama sehingga akan terjadi dialog yang efektif. Meminjam istilah dari Freire (1984) sistem pendidikan alternatif ini dinamakan "problem-posing education" yang memungkinkan konsientisasi (penyadaran diri).

Implikasi dalam pelaksanaan KIMBis, sistem ini akan menumbuhkan sinergitas yang tinggi karena semua pelaku diposisikan sama. KIMBis, masyarakat, LSM, SKPD, SKPP, dan dunia usaha semuanya akan belajar, sehingga semua pihak akan dapat mengambil pelajaran yang dapat meningkatkan kualitas dirinya. KIMBis dan masyarakatnya akan mempunyai mekanisme pemberdayaan diri yang kuat, sementara praktisi pemberdayaan (dalam hal ini pemerintah, LSM dan dunia usaha) akan semakin mapan dalam bidangnya.

Dalam hal ini, sinergitas tidak hanya berimplikasi terhadap efektifitas dan efisiensi program pemberdayaan saat ini, namun jika semua pihak dapat mengambil pelajaran maka program pemberdayaan dimasa yang akan datang dapat jauh lebih efektif dan efisien. Gambar 1 merupakan skema sinergitas tersebut yang dimodifikasi dari konsep Freire (1984). 


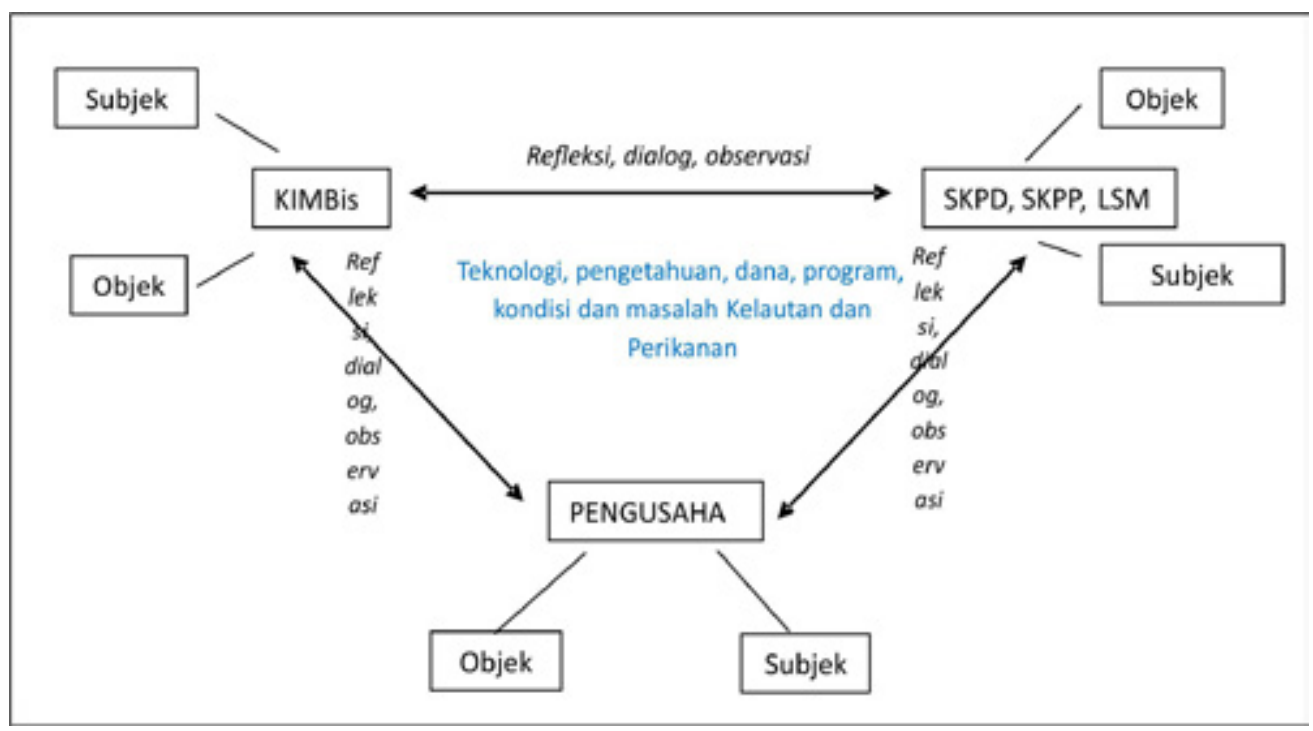

Sumber: dimodifikasi dari Freire (1984)

Gambar 1. Skema Upaya Membangun Sinergitas Antar pelaku Pemberdayaan

Implementasi konsep pada Gambar 1, dapat dilihat dalam proses pelatihan yang diselenggarakan oleh KIMBis Subang dalam meningkatkan keterampilan para nelayan dibidang perbengkelan mesin kapal dan pelatihan kerajinan tangan berbahan baku kerang. Kegiatan tersebut dilakukan secara kolaboratif antara SKPD, BPSDM Badan Pengembangan Sumber Daya Manusia (BPSDM), LSM, dan KIMBis bersama masyarakat.

Unsur SKPD yang terlibat dalam kegiatan ini adalah Dinas Kelautan dan Perikanan Kabupaten Subang yang tidak hanya berkontribusi dalam pembiayaan kegiatan, tapi bersama KIMBis turut berperan dalam mengatur jalannya pelatihan. Dalam hal ini, DKP belajar bagaimana mengelola sebuah kegiatan dan mengetahui lebih jelas tugas dan fungsi KIMBis, serta mendapat masukan sejauh mana kemampuan nelayan dalam mengelola usahanya. Hal ini akan menjadi bahan bagi DKP Subang untuk pelatihan di masa yang akan datang.

BPSDM KP sebagai narasumber dalam hal ini adalah widyaiswara dari Balai Pendidikan dan Pelatihan Perikanan (BP3) Tegal, selain menjadi subjek pemberdayaan dengan memberikan ilmu perbengkelan, ia pun mengambil pelajaran bagaimana menghadapi masyarakat yang mempunyai kharakter seperti nelayan Subang. Selain itu, terdapat teknik-teknik tertentu yang dipakai oleh nelayan Subang yang dapat dijadikan bahan untuk diteliti lebih jauh.

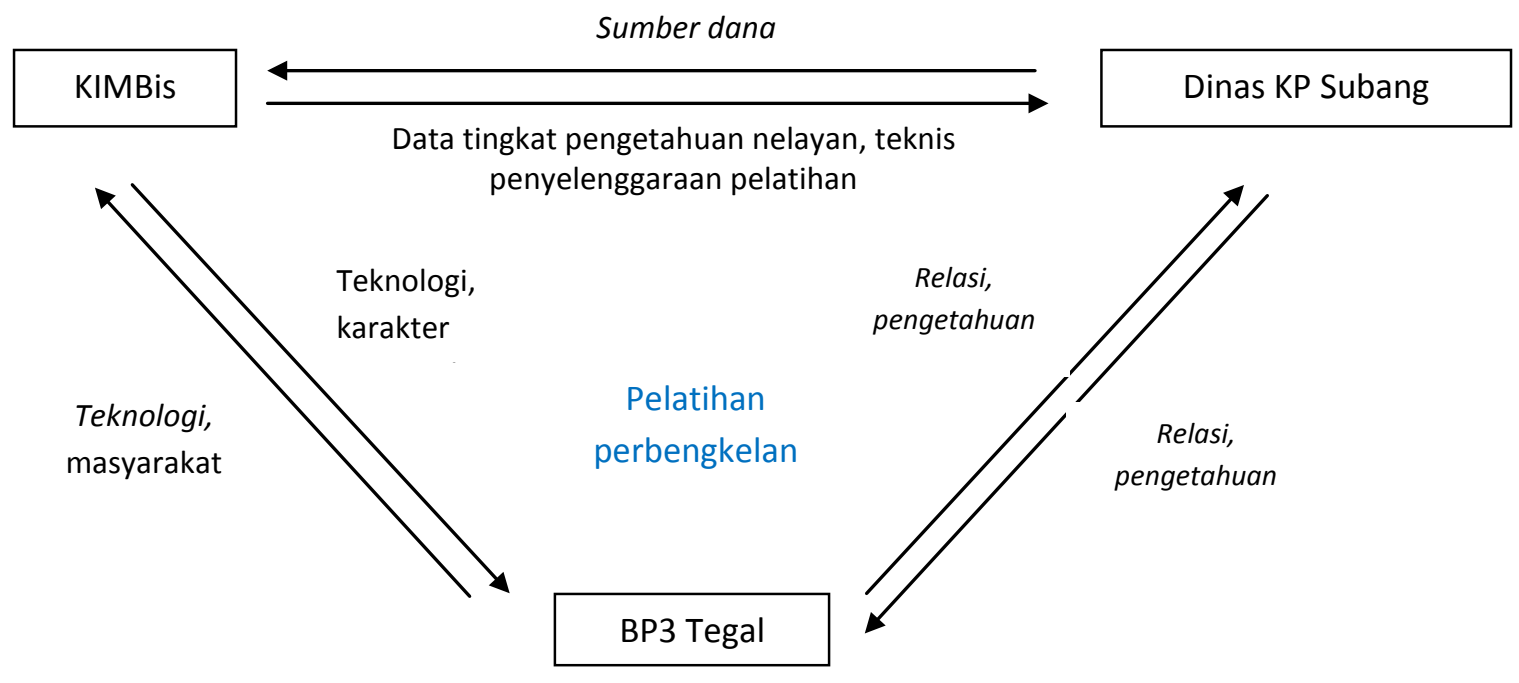

Sumber: data primer diolah, 2013

Gambar 2. Skema Upaya Membangun Sinergitas Antar Pelaku Pemberdayaan dalam Kegiatan Pelatihan Perbengkelan yang dilaksanakan Oleh KIMBis Subang. 


\section{LANGKAH STRATEGIS KIMBIS MEMBANGUN SINERGITAS}

Langkah strategis yang dapat dilakukan agar SKPP, SKPD, LSM dan KIMBis dapat bersinergi dalam upaya memfungsikan KIMBis sebagai lembaga pemberdayaan adalah;

1. Proses pembentukan harus melibatkan pemangku kepentingan lokal yang terkait dengan pemberdayaan nelayan, misalnya Dinas Kelautan dan Perikanan Kabupaten, aparat pemerintahan kelurahan, tokoh-tokoh masyarakat yang representatif, lembaga ekonomi lokal, organisasi dan LSM lokal; kegiatan ini merupakan langkah awal dalam membangun jaringan yang berlandaskan partisipasi.

2. Membuat program kerja yang mengarah pada kemandirian KIMBis yang dilakukan secara partisipatif;

3. Membangun percaya diri (self confidence) para pengurus KIMBis untuk dapat membuat jaringan kerja secara mandiri sehingga dapat meyakinkan pihak yang berkentingan untuk bekerja sama. Kepercayaan diri menurut Lauter merupakan suatu sikap atau keyakinan atas kemampuan diri sendiri sehingga dalam tindakan-tindakannya tidak terlalu cemas, merasa bebas untuk melakukan hal-hal yang sesuai keinginan dan tanggung jawab atas perbuatannya, sopan dalam berinteraksi dengan orang lain, memiliki dorongan prestasi serta dapat mengenal kelebihan dan kekurangan diri sendiri (Lestari, 2008). KIMBis yang mempunyai kepercayaan diri yang tinggi akan memiliki ciri-ciri tidak mementingkan diri sendiri (toleransi), tidak tergantung pada inisiatif KIMBis Pusat, dan selalu bersikap optimis.

4. Melakukan sosialisasi dan koordinasi dengan berbagai stakeholder. Kegiatan ini terus dilakukan tidak saja dalam pertemuan formal, namun juga dalam pertemua informal. Materi dalam kegiatan ini tidak hanya mencakup kegiatan yang akan dan sedang dilaksanakan KIMBis namun juga menyangkut harapan KIMBis dan feedback bagi partner KIMBis.

5. Menjaga hubungan non formal untuk menumbuhkan ikatan emosional. Adanya ikatan emosional dalam hubungan antar pelaku dalam pemberdayaan KIMBis menjadi sebuah strategi yang penting mengingat ikatan emosional merupakan sebuah faktor yang menyebabkan pihak-pihak tersebut mempunyai keinginan untuk mempertahankan hubungan tersebut.

\section{KESIMPULAN}

KIMBis sebagai wadah membangun sinergitas antar pelaku pemberdayaan harus konsekuen menerapkan beberapa prinsip dalam mekanisme pelaksanaannya yaitu prinsip partnership, partisipatif menuju emansipatif, dan KIMBis sebagai sarana problemposing education. KIMBis dengan prinsip partnershipnya memposisikan masing-masing pelaku yang mempunyai peran dan kapasitas berbeda untuk saling melengkapi dan bekerjasama dalam memberdayakan masyarakat. Partisipatif merupakan prinsip yang harus diterapkan dalam setiap pengambilan keputusan. Keterlibatan pemerintah dalam prinsip ini harus semakin dikurangi sehingga terwujud prinsip emansipatif yang mengarah kepada kemandirian KIMBis. Selain itu, KIMBis berperan sebagai ruang publik, dimana setiap pelaku pemberdayaan dapat saling memberi dan mengambil pelajaran dari proses pemberdayaan yang sedang berlangsung sehingga dapat memperbaiki proses pemberdayaan yang akan datang.

Langkah strategis yang dilakukan oleh KIMBis adalah pelibatan berbagai stakeholder dalam proses pembentukan, pembuatan program kerja secara partisipatif, membangun rasa percaya diri KIMBis, selalu melakukan sosialisasi dan koordinasi dengan berbagai pihak yang berkepentingan dan menumbuhkan ikatan emosional.

\section{DAFTAR PUSTAKA}

Lestari, F.L. 2008. Usaha Pembina Dalam Menumbuhkan Rasa Percaya Diri Pada Remaja Anak Asuh Panti Putri Aisyiyah Serangan Yogyakarta. Skripsi. Jurusan Pendidikan Islam Fakultas Tarbiyah. Universitas Islam Negeri Sunan Kalijaga. Yogyakarta.

Freire, P. 1979. Pendidikan, Pembebasan dan Perubahan Sosial. PT. Sangkala Putsar. Jakarta.

Ife, J. 2002. Community Development: Community-based alternatives in an age of globalization. Pearson Education Australia Pty Limited.

Kurniasari N dan Reswati. 2011. Memaknai Program Pemberdayaan Ekonomi Masyarakat Pesisir. Buletin Riset Sosial Ekonomi Kelautan dan Perikanan Vol. 6 No. 1, Tahun 2011. Balai Besar Penelitian Sosial Ekonomi Kelautan dan Perikanan. Jakarta.

Prijono O S, Pranarka. AMW. 1996. Pemberdayaan: Konsep, Kebijakan dan Implementasi. CSIS. Jakarta.

Poloma, M. 1979. Sosiologi Kontemporer. PT. Raja Grafindo Persada. Jakarta. 